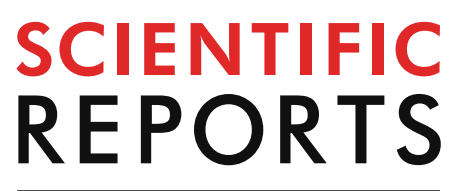

natureresearch

Check for updates

\title{
Administration of cardiac
} mesenchymal cells modulates innate immunity in the acute phase
of myocardial infarction in mice

Yi Kang ${ }^{1,4}$, Marjan Nasr ${ }^{1,4}$, Yiru Guo ${ }^{2}$, Shizuka Uchida ${ }^{3}$, Tyler Weirick ${ }^{3}$, Hong Li ${ }^{1}$, Jae Kim ${ }^{1}$, Joseph B. Moore 4th ${ }^{1}$, Senthilkumar Muthusamy ${ }^{1}$, Roberto Bolli ${ }^{2}$ \& Marcin Wysoczynski ${ }^{1 凶}$

Although cardiac mesenchymal cell (CMC) therapy mitigates post-infarct cardiac dysfunction, the underlying mechanisms remain unidentified. It is acknowledged that donor cells are neither appreciably retained nor meaningfully contribute to tissue regeneration-suggesting a paracrinemediated mechanism of action. As the immune system is inextricably linked to wound healing/ remodeling in the ischemically injured heart, the reparative actions of CMCs may be attributed to their immunoregulatory properties. The current study evaluated the consequences of CMC administration on post myocardial infarction (MI) immune responses in vivo and paracrine-mediated immune cell function in vitro. CMC administration preferentially elicited the recruitment of cell types associated with innate immunity (e.g., monocytes/macrophages and neutrophils). CMC paracrine signaling assays revealed enhancement in innate immune cell chemoattraction, survival, and phagocytosis, and diminished pro-inflammatory immune cell activation; data that identifies and catalogues fundamental immunomodulatory properties of CMCs, which have broad implications regarding the mechanism of action of CMCs in cardiac repair.

Although cell therapy is a promising and safe approach for the treatment of heart failure $(\mathrm{HF})^{1,2}$, the mechanism whereby injected cells improve heart function remains poorly understood. Preclinical studies have shown that improvement of left ventricular (LV) function after cell therapy is associated with increased angiogenesis and reduction of fibrosis and inflammation ${ }^{1,3-7}$. It is now well accepted that injected cells do not improve heart function by differentiating into cardiomyocytes and endothelium ${ }^{1,8-12}$. The negligible long-term survival of injected cells suggests that cell therapy activates endogenous mechanisms of repair via secretion of paracrine factors ${ }^{1,6-12}$, the nature of which, however, remains unclear.

Myocardial damage due to ischemic injury elicits an inflammatory response ${ }^{13-15}$. In the first phase, neutrophils and pro-inflammatory monocytes are recruited to facilitate the degradation of dead tissue via secretion of proteolytic enzymes ${ }^{16-19}$. In the subsequent few days, the neutrophil response resolves and monocytes differentiate to reparative macrophages which remove degraded dead tissue and apoptotic cells via efferocytosis, but also secrete cytokines to facilitate angiogenesis and activate fibroblasts ${ }^{13,14}$. Activation of fibroblasts and their conversion to myofibroblasts facilitates the deposition of extracellular matrix and scar formation and also results in resolution of inflammation ${ }^{13-15,20-22}$. A dysregulated immune response leads to the failure of timely scar formation which results in expansion of the scar area and further damage of the remaining cardiac muscle. Moreover, systemic depletion of neutrophils or macrophages leads to disarrangement of the reparative immune response, failure of infarct healing, and scar expansion leading to cardiac rupture ${ }^{18,19,23-25}$. Thus, immune cells are indispensable for the wound healing response to ischemic injury. Because cell therapy has salutary effects on cardiac recovery after myocardial infarction (MI), it can be hypothesized that injected cells activate the reparative immune response to preserve cardiac function.

${ }^{1}$ Diabetes and Obesity Center, University of Louisville School of Medicine, 580 South Preston St. - Rm 204B, Louisville, KY 40202, USA. 'Institute of Molecular Cardiology, University of Louisville School of Medicine, Louisville, KY, USA. ${ }^{3}$ Cardiovascular Innovation Institute, Univerity of Louisville School of Medicine, Louisville, KY, USA. ${ }^{4}$ These authors contributed equally: Yi Kang and Marjan Nasr. ${ }^{\circledR}$ email: m0wyso01@louisville.edu 
We have previously demonstrated that cardiac mesenchymal cells (CMCs) exert significant reparative actions after acute $\mathrm{MI}^{5,26}$. Although the immune system is a necessary component of myocardial repair, it is unknown whether the improvement in cardiac function after cell therapy is due to immunoregulatory actions of CMCs. Therefore, the purpose of this study was to determine whether administration of CMCs soon after MI regulates the reparative immune response. We found that CMC injection recruits innate immune cells (monocytes, macrophages, neutrophils) but has no effect on adaptive immunity (B and $\mathrm{T}$ cells). In vitro data demonstrated that the secretome of CMCs exerts chemotactic activity towards neutrophils and monocytes/macrophages, enhances survival of neutrophils and macrophages, enhances phagocytosis, and inhibits pro-inflammatory activation of macrophages. These observations suggest that CMCs have immunomodulatory properties that could contribute to $\mathrm{CMC}$-induced myocardial repair. Identification of reparative immune pathways enhanced by cell therapy would advance our understanding of the mechanism of action of cell therapy and may provide a new therapeutic target for improving myocardial repair without administration of cell products.

\section{Materials and methods}

Isolation and culture of CMCs. All procedures were approved by the University of Louisville Institutional Animal Care and Use Committee and were in accordance with NIH guidelines. The euthanasia procedures were consistent with the AVMA Guidelines for the Euthanasia. CMCs were isolated as previously described ${ }^{5}$. Briefly, myocardial cells were isolated from 12 to 15 weeks old, male C57BL6 mice (The Jackson Laboratory). Mice were euthanized by sodium pentobarbital injection $(100 \mathrm{mg} / \mathrm{kg}$ i.p.). The hearts were excised, washed in room temperature PBS, minced into small pieces, and enzymatically dissociated with Collagenase II $(5 \mathrm{mg} / \mathrm{mL}$ in PBS; Worthington) with gentle agitation for $45 \mathrm{~min}$ at $37^{\circ} \mathrm{C}$. After Collagenase II inactivation with DMEM/F12 medium containing $10 \%$ FBS, cells were centrifuged at $600 \times g$ for $10 \mathrm{~min}$. The collected cell pellet was suspended in growth medium consisting of DMEM/F12 (Invitrogen), 10\% FBS (Seradigm, VWR), bFGF (10 ng/ml), EGF (10 ng/ml), ITS (insulin/transferrin/selenium), glutamine, and Pen-Strep. The CMCs were cultured and passaged twice before cryopreservation in liquid nitrogen. Upon thawing, the cells were propagated in growth media for 2-6 passages prior to in vitro or in vivo experiments.

Murine model of MI. Studies were performed in C57BL6/J female mice (age 12-15 weeks) purchased from The Jackson Laboratory (Bar Harbor, ME, USA). Mice were maintained in microisolator cages under specific pathogen-free conditions in a room with a temperature of $24{ }^{\circ} \mathrm{C}, 55-65 \%$ relative humidity, and a 12-h lightdark cycle. The murine model of myocardial ischemia and reperfusion has been described in detail ${ }^{5,26}$. Briefly, mice were anesthetized with sodium pentobarbital $(60 \mathrm{mg} / \mathrm{kg}$ i.p.) and ventilated using carefully selected parameters. The chest was opened through a midline sternotomy, and a nontraumatic balloon occluder was implanted around the mid-left anterior descending coronary artery using an 8-0 nylon suture. To prevent hypotension, blood from a donor mouse was given at serial times during surgery. Rectal temperature was carefully monitored and maintained between 36.7 and $37.3{ }^{\circ} \mathrm{C}$ throughout the experiment. In all groups, MI was produced by a 60 -min coronary occlusion followed by reperfusion. Successful performance of coronary occlusion and reperfusion was verified by visual inspection (i.e., by noting the development of a pale color in the distal myocardium after inflation of the balloon and the return of a bright red color due to hyperemia after deflation) and by observing S-T segment elevation and widening of the QRS on the ECG during ischemia and their resolution after reperfusion).

Preparation of cells for injection. As previously described ${ }^{4}$, on the day of injection, cells were $60-80 \%$ confluent. The cell monolayer was washed two times with room temperature PBS to remove debris and dead cells. Subsequently, cells were harvested by enzymatic digestion with $0.25 \%$ trypsin-EDTA (Invitrogen). The resulting cell suspension was trypsin-inactivated with DMEM/F12 supplemented with $10 \% \mathrm{FBS}$. After centrifugation at $600 \times g$ for $10 \mathrm{~min}$ at RT, cells were suspended in PBS and counted using a hemocytometer. Next, cells were filtered through a $40-\mu \mathrm{m}$ filter and centrifuged for $10 \mathrm{~min}$ at $600 \times \mathrm{g}$ at RT. A total of $0.5 \times 10^{6}$ cells were suspended in $40 \mu \mathrm{L}$ of sterile PBS ( $\mathrm{pH}$ 7.4) at room temperature and transported to the mouse surgery laboratory for injection. Extra cell suspension volume was prepared to account for the dead space in the syringe and needle used for injections.

Intramyocardial cell delivery. At $48 \mathrm{~h}$ after MI, mice were anesthetized and the chest reopened through a central thoracotomy. Cells $\left(0.5 \times 10^{6}\right.$ cells in $\left.40 \mu \mathrm{L}\right)$ or an equivalent volume of PBS vehicle were injected intramyocardially using a 30 -gauge needle. A total of four injections $(10 \mu \mathrm{L}$ each $)$ were made in the peri-infarct region in a circular pattern, at the border between infarcted and noninfarcted myocardium, as described ${ }^{5}$.

Flow cytometric analysis in vivo. At $2 \mathrm{~d}$ after MI or sham operation, or at $7 \mathrm{~d}$ after cell or vehicle injection ( $9 \mathrm{~d}$ after MI), mice were euthanized by sodium pentobarbital injection $(100 \mathrm{mg} / \mathrm{kg}$ i.p.). The hearts were excised and perfused with cold PBS for $10 \mathrm{~min}$ to wash out peripheral blood, minced into small pieces, enzymatically dissociated with Collagenase II ( $5 \mathrm{mg} / \mathrm{mL}$ in PBS; Worthington) with gentle agitation for $45 \mathrm{~min}$ at $37^{\circ} \mathrm{C}$, and washed with PBS. Next, myocardial cells were isolated at the interface of $70 \%$ and $30 \%$ of discontinuous Percoll gradient after centrifugation at $1,750 \times g$ at room temperature for $20 \mathrm{~min}$. Subsequently, collected cells were washed in PBS and stained with a cocktail of antibodies. The following monoclonal antibodies were used for flow cytometry analyses: anti-Ly-6G (eBioscience, clone 1A8), anti-CD11b (eBioscience, clone M1/70), anti-CD115 (eBioscience, clone AFS98), anti-Ly6C (eBioscience, clone HK1.4), anti-CD3 (eBioscience, clone 145-2C11), anti-CD8a (eBioscience, clone 53-6.7), anti-CD4 (eBioscience, clone GK1.5), anti-CD19 (eBioscience, clone 1D3), anti-CD90.2 (eBioscience, clone 30H12), anti-NK1.1 (eBioscience, clone PK136), anti-CD49b (eBiosci- 
ence, cloneDX5), anti-MHC Class II (eBioscience, clone AF6-120.1), anti-CD11c (eBioscience, clone N418). Cells

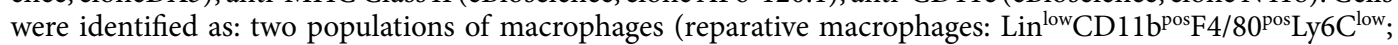
pro-inflammatory macrophages: Lin ${ }^{\text {low }} \mathrm{CD} 11 \mathrm{~b}^{\text {pos }} \mathrm{F} 4 / 80^{\text {pos }} \mathrm{Ly} 6 \mathrm{C}^{\text {high }}$ ), two populations of monocytes (reparative monocytes: $\quad$ Lin $^{\text {low }} \mathrm{CD} 11 \mathrm{~b}^{\text {pos }} \mathrm{F} 4 / 80^{\text {neg }} \mathrm{MHCII}^{\text {neg }} \mathrm{CD} 11 \mathrm{c}^{\text {neg }}$ Ly6C $\mathrm{C}^{\text {low; }}$ pro-inflammatory monocytes: $\mathrm{Lin}^{\text {low }} \mathrm{CD} 11 \mathrm{~b}^{\text {pos }} \mathrm{F} 4 / 80^{\text {neg }} \mathrm{MHCII}{ }^{\text {neg }} \mathrm{CD} 11 \mathrm{c}^{\text {neg }} \mathrm{Ly} 6 \mathrm{C}^{\text {high }}$ ), and two populations of neutrophils (pro-inflammatory N1 neutrophils: CD11b ${ }^{\text {pos }}$ Ly $6 \mathrm{G}^{\text {pos }} \mathrm{CD} 206^{\text {neg }}$; reparative $\mathrm{N} 2$ neutrophils: $\left.\mathrm{CD} 11 \mathrm{~b}^{\text {pos }} \mathrm{Ly} 6 \mathrm{G}^{\text {pos }} \mathrm{CD} 206^{\text {pos }}\right)$. The data analysis was performed with FlowJo software.

Isolation of bone marrow macrophages. 12-15-weeks old, male C57BL6 mice (The Jackson Laboratory) were euthanized by sodium pentobarbital injection (100 mg/kg i.p.). Tibia and femur bones were flushed with ice-cold PBS using a 21-gauge needle. The collected bone marrow cell pellet was suspended in a growth medium consisting of DMEM/F12 (Invitrogen), 10\% FBS (Seradigm, VWR), M-CSF (50 ng/ml), and Pen-Strep. A single-cell suspension was plated in the tissue culture flask. After $24 \mathrm{~h}$, floating cells were removed and adherent cells were expanded for 7-10 d with media change every other day. Macrophage purity was determined by co-expression of CD11b and F4/80 markers, evaluated with flow cytometry.

Isolation of bone marrow neutrophils. Bone marrow cells were isolated from tibia and femur bones as described above (isolation of bone marrow macrophages). Bone marrow neutrophils were isolated with a Neutrophils isolation kit (Miltenyi Biotech), according to manufacturer's recommendations. Briefly, neutrophils were isolated by depletion of non-target cells. Non-target cells were labeled with a cocktail of biotin-conjugated monoclonal antibodies, as primary labeling reagent, followed by anti-biotin monoclonal antibodies conjugated to MicroBeads as a secondary labeling reagent. The magnetically labeled non-target cells were depleted by retaining them on LS MACS Column in the magnetic field of a MACS separator, while unlabeled neutrophils ran through the column. The neutrophils' purity was evaluated by CD11b and Ly6G co-expression with flow cytometry, as described ${ }^{27}$.

Real-time PCR. As described ${ }^{28}$, total mRNA was isolated with the RNeasy Mini Kit (Qiagen) and reversetranscribed with TaqMan Reverse Transcription Reagents (Applied Biosystems). Quantitative assessment of mRNA pro-inflammatory (IL1b, Il6, Tnfa, Ccl2, Ccl5) and anti-inflammatory markers (Il10, Tgfb, 1, Thgf2, Tgfb3) and $\beta 2$-microglobulin was performed by qRT-PCR using StepOne (Applied Biosystems). A 10- $\mu$ L-reaction mixture containing $5 \mu \mathrm{L}$ of SYBR Green PCR Master Mix and forward and reverse primers was used. The threshold cycle $(\mathrm{Ct})$, i.e., the cycle number at which the amount of amplified gene of interest reached a fixed threshold, was subsequently determined. Relative quantitation of mRNA expression was performed with the comparative $\mathrm{Ct}$ method. The relative quantitative value of the target, normalized to an endogenous control ( $\beta 2$-microglobulin gene) and relative to a calibrator, was expressed as $2^{-\Delta \Delta \mathrm{Ct}}$ (-fold difference), where $\Delta \mathrm{Ct}=(\mathrm{Ct}$ of target genes] $)-(\mathrm{Ct}$ of endogenous control gene [ $\beta 2$-microglobulin] $)$, and $\Delta \Delta \mathrm{Ct}=(\Delta \mathrm{Ct}$ of samples for target gene $)-(\Delta \mathrm{Ct}$ of calibrator for the target gene). To avoid the possibility of amplifying contaminating DNA (1) all of the primers for realtime RT-PCR were designed to contain an intron sequence for specific cDNA amplification; (2) reactions were performed with appropriate negative controls (template-free controls); (3) uniform amplification of the products was rechecked by analyzing the melting curves of the amplified products (dissociation graphs); and (4) the melting temperature $(\mathrm{Tm})$ was $57-60^{\circ} \mathrm{C}$, and the probe $\mathrm{Tm}$ was at least $10^{\circ} \mathrm{C}$ higher than primer $\mathrm{Tm}$.

Statistical analysis. Results are shown as mean \pm SEM. Statistical analyses (GraphPad 7.0d) were performed with Student's t-tests or one-way ANOVA followed by Student's $t$ tests with Bonferroni correction, as appropriate. Differences were considered statistically significant when $P<0.05$.

\section{Results}

The magnitude and kinetics of immune cell infiltration are highly dependent on the model of myocardial injury. Compared with non-reperfused MI models, ischemia followed by reperfusion is associated with a reduction of infiltrating leukocytes and tends to shift the kinetics of the immune response towards faster resolution ${ }^{17}$. Therefore, first, we profiled the immune cells in the myocardium at the time of CMC injection in our model of 60-min ischemia followed by reperfusion. Single-cell suspensions of digested hearts at $2 \mathrm{~d}$ after MI or sham operation were labeled with fluorescently labeled antibodies.

Profile of myeloid immune cells $2 \mathbf{d}$ after MI. Flow cytometry defined neutrophils as CD $11 b^{\text {high }}$ Ly6G ${ }^{\text {high }}$ cells. These were further stratified into CD206 $6^{\text {low }}$ and CD206 $6^{\text {high }}$ subpopulations representing N1 and N2 neutrophils, respectively, (Fig. 1A), as previously described ${ }^{29}$. We found a low number of neutrophils in shamoperated mice $(29.9 \pm 7.7$ cells per $\mathrm{mg}$ of tissue), but this number increased markedly in hearts after I/R injury (740.8 \pm 96.2 cells per mg of tissue, $P<0.01$ ). Characterization of neutrophil subpopulations showed a higher contribution of pro-inflammatory (N1) cells, which comprised $95 \%$ of total neutrophils in the heart after MI, compared with anti-inflammatory (N2) cells $(667.9 \pm 89.5$ vs $37.1 \pm 4.3$ cells per mg of tissue, respectively, $P<0.01)$ (Fig. 1D). Next, flow cytometry detected monocytes as CD11b ${ }^{\text {high }}$ (CD90/B220/CD49b/NK1.1/Ly6G) ${ }^{\text {low }}(\mathrm{F} 4 / 80 /$ MHCII/CD11c) $)^{\text {low }}$ cells, and divided them into two sub-populations: pro-inflammatory (Ly6C ${ }^{\text {high }}$ ) and antiinflammatory (Ly6C low $)$ monocytes (Fig. 1B), as previously described ${ }^{18}$. We found that compared with sham operation both Ly6C $\mathrm{C}^{\text {high }}$ and Ly6C $\mathrm{C}^{\text {low }}$ monocyte subpopulations were increased after MI (Ly6 $\mathrm{C}^{\text {high }}: 12.9 \pm 5.5$ vs $210.5 \pm 62.7$ cells per mg of tissue, respectively, $P<0.05$; Ly6C low $: 18.5 \pm 1.0$ vs $105.9 \pm 22.6$ cells per mg of tissue, $P<0.05)$. The pro-inflammatory subpopulation constituted $\sim 67 \%$ of total monocytes present in the heart at $2 \mathrm{~d}$ 
A.
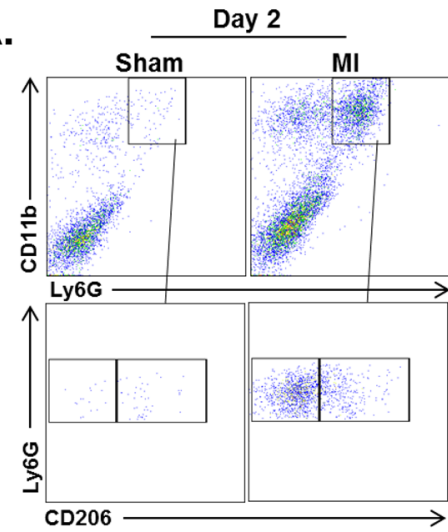

D.
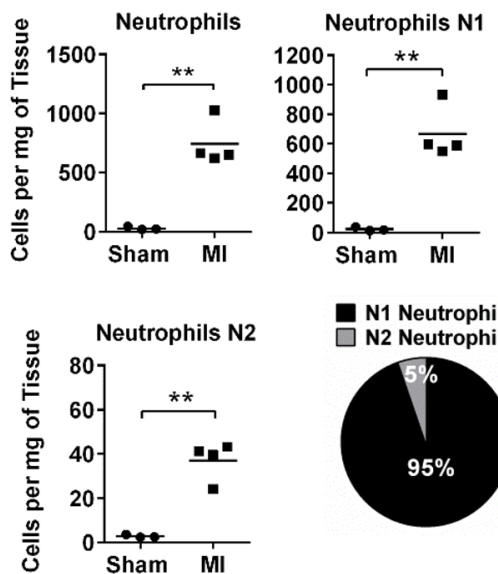

G.

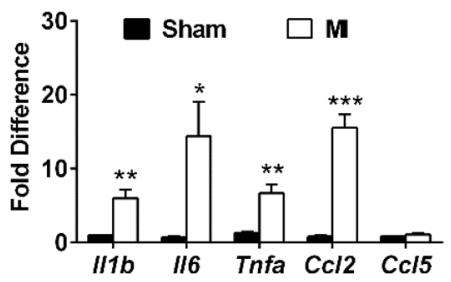

B.

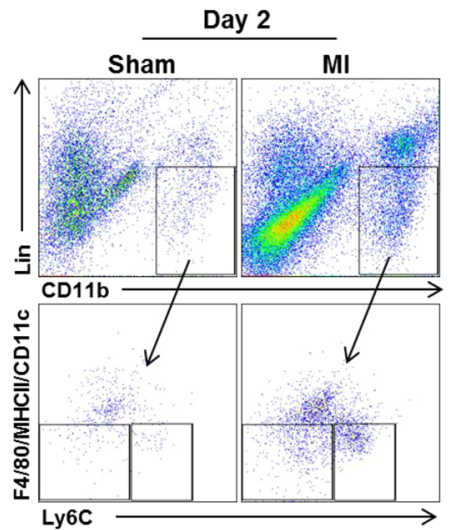

E.

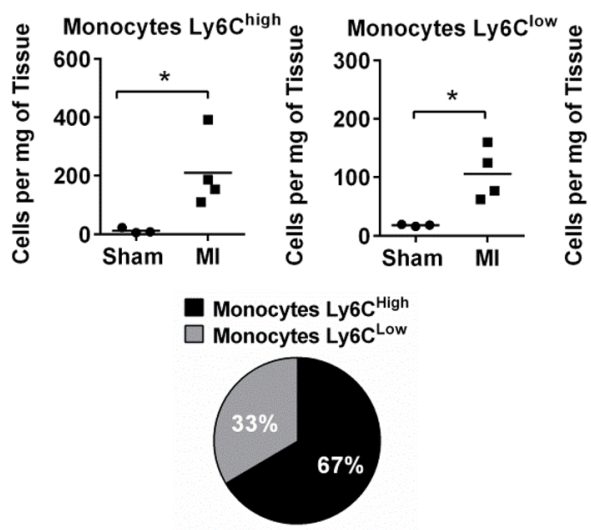

H.

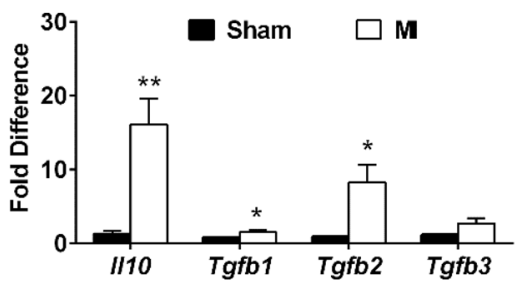

C.

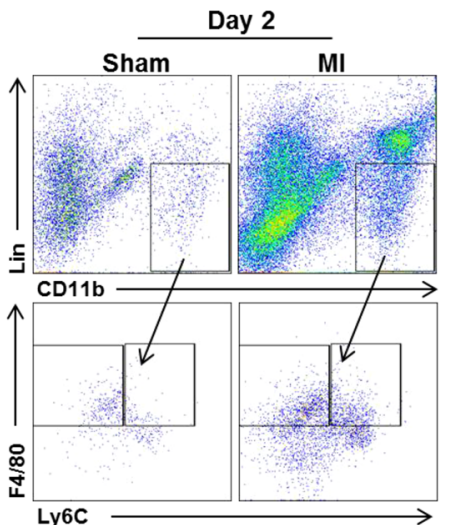

F.

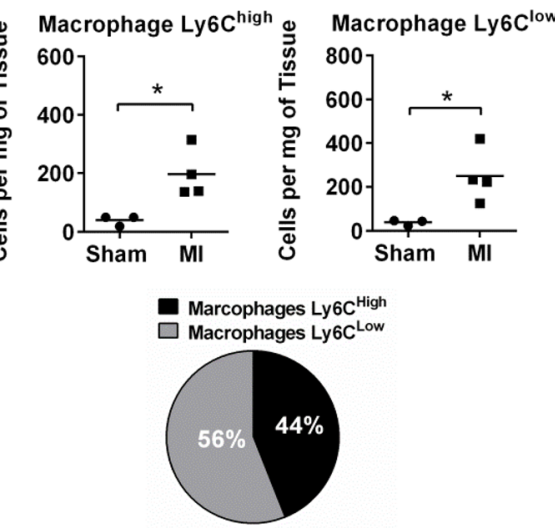

Figure 1. Mouse hearts $2 \mathrm{~d}$ after MI are infiltrated in pro-inflammatory immune cells. Cell suspensions of enzymatically digested hearts from sham and MI mice were stained with fluorescently labeled antibodies. Representative dot plots identified: (A) neutrophils as CD11 $b^{\text {pos }}$ Ly $6 G^{\text {pos }}$ cells, which were stratified into N1 $\left(C D 206^{\text {neg }}\right)$ and N2 (CD206 $\left.{ }^{\text {pos }}\right)$ subpopulations; (B) monocytes $\operatorname{Lin}^{\text {neg }}$ CD11b ${ }^{\text {pos }}(\text { F4/80/CD11c/MHCII })^{\text {low }}$ with Ly6C $C^{\text {high }}$ and Ly6C $C^{\text {low }}$ expression; (C) macrophages Lin ${ }^{\text {neg }} \mathrm{CD} 11 \mathrm{~b}^{\text {pos }} \mathrm{F} 4 / 80^{\text {high }}$ with Ly6C $\mathrm{C}^{\text {high }}$ and Ly6Clow expression. Numerical representations of neutrophils (D), monocytes $(\mathbf{E})$, and macrophages $(\mathbf{F})$ and their subpopulations per $\mathrm{mg}$ of tissue; pie chart represents contribution of pro-inflammatory and anti-inflammatory cell subpopulations. Number of cells shown as mean; sham $n=3$, MI $n=4 ;{ }^{\star} P<0.05$; ${ }^{\star *} P<0.01$ (unpaired t test). Quantitative PCR on mRNA isolated from hearts $2 \mathrm{~d}$ after sham and MI. Messenger RNA expression of proinflammatory $(\mathbf{G})$ and anti-inflammatory $(\mathbf{H})$ cytokines and chemokines in whole hearts $2 \mathrm{~d}$ after sham and MI. Data are means \pm SEM; sham $\mathrm{n}=4, \mathrm{MI}=4 ;{ }^{\star} P<0.05 ;{ }^{\star \star} P<0.01$; ${ }^{\star \star \star} P<0.001$ (unpaired $t$ test).

after MI (Fig. 1E). Two subpopulations of macrophages with Ly6 $\mathrm{C}^{\text {high }}$ and Ly6C $\mathrm{C}^{\text {low }}$ expression were detected within the Lin ${ }^{\text {low }} \mathrm{CD} 11 \mathrm{~b}^{\text {high }} \mathrm{F} 4 / 80^{\text {high }}$ population (Fig. 1C). Both subpopulations of macrophages were significantly increased in hearts after MI compared with sham-operated mice (Ly6C ${ }^{\text {high }}, 40.1 \pm 10.2$ vs $196.4 \pm 42.0$ cells per $\mathrm{mg}, P<0.05$; and Ly6C low $39.3 \pm 7.3$ vs $250.0 \pm 61.7$ cells per $\mathrm{mg}$ of tissue, $P<0.05)$ (Fig. $1 \mathrm{~F}$ ). These data indicate that at the time of $\mathrm{CMC}$ injection ( $2 \mathrm{~d}$ after $\mathrm{MI})$, hearts are in the initial pro-inflammatory phase as indicated by high levels of neutrophils and pro-inflammatory monocytes.

Profile of B and T lymphocytes $2 \mathbf{d}$ after MI. Both T and B cells are involved in myocardial healing and regulation of immune response after $\mathrm{MI}^{14,30-34}$. Flow cytometry identified $\mathrm{B}$ cells in cell suspensions from hearts obtained $2 \mathrm{~d}$ after sham operation or $\mathrm{MI}$ as $\mathrm{CD} 3^{\text {low }} \mathrm{B} 220^{\text {high }}$ or $\mathrm{CD} 3^{\text {low }} \mathrm{CD} 19^{\text {high }}$. B cells, detected with both sets 
of markers, compared with sham-operated mice were elevated after MI (B220 high, $5.4 \pm 1.3$ vs $35.7 \pm 16.8$ cells per mg of tissue; CD19high, $22.0 \pm 2.9$ vs $71.4 \pm 23.2$ cells per mg of tissue); however, these differences did not reach statistical significance (Supplementary Fig. 1). Next, we found a significant increase in total T CD3 ${ }^{\text {pos }}$ cells in infarcted hearts $(4.8 \pm 0.6$ vs $17.7 \pm 4.1$ cells per mg of tissue, $P<0.05)$. T cells were further stratified into cytotoxic (Tc) $\mathrm{CD} 3^{\text {high }} \mathrm{CD} 8^{\text {high }}$ and helper $(\mathrm{Th}) \mathrm{CD} 3^{\text {high }} \mathrm{CD} 4^{\text {high }}$. Both populations were increased after MI, but only the Tc elevation reached statistical significance (Th, $0.5 \pm 0.1$ vs $2.6 \pm 1.3$ cells per mg of tissue; Tc, $1.1 \pm 0.6$ vs $7.9 \pm 2.1$ cells per mg of tissue, $P<0.05$ ) (Supplementary Fig. 1). Previous reports have shown that B and T cell infiltration peaks at the time of resolution/repair and in the scar maturation phase $\mathrm{e}^{17}$. The relatively low number of lymphocytes at $2 \mathrm{~d}$ after MI suggests that, at this time, hearts are still in the early, pro-inflammatory phase.

Expression of pro- and anti-inflammatory factors $\mathbf{2} \mathbf{d}$ after MI. To further examine the inflammatory milieu of the myocardium at the time of CMC injection, we evaluated the tissue expression of proinflammatory and anti-inflammatory cytokines with qPCR. We found augmented expression of the classical pro-inflammatory cytokines $I l 1 b$, Il6, Tnfa ( 6.0, 14.4, and 6.7 fold increase, respectively) and the pro-inflammatory chemokine $\mathrm{Ccl} 2(\sim 15.5$-fold increase) in hearts $2 \mathrm{~d}$ after MI as compared with sham-operated controls (Fig. 1G). At the same time, expression of anti-inflammatory and pro-reparative cytokines (Illo, $T g f b 1, T g f b 2$, and $T g f b 3)$ was increased $(\sim 16.0,1.6,8.2$, and 2.7-fold increase, respectively) (Fig. $1 \mathrm{H})$. The appearance of these anti-inflammatory cytokines at the mRNA level may indicate the beginning of the resolution of the inflammation phase after $\mathrm{MI}^{14,20}$.

Intramyocardial injection of CMCs recruits neutrophils. Neutrophils infiltrating ischemic myocardium secrete proteolytic enzymes that degrade extracellular matrix and dead cells, which supports efferocytosis and removal of dead tissue by macrophages ${ }^{14,19}$. Next, we evaluated the effect of CMCs on neutrophil infiltration. CMCs $\left(0.5 \times 10^{6}\right)$ were injected intramyocardially $2 \mathrm{~d}$ after MI. At $7 \mathrm{~d}$ after cell injection, hearts were harvested and subjected to enzymatic digestion. The myocardial cell suspensions were stained with monoclonal antibodies and quantified with flow cytometry. We found that compared with vehicle controls the CD11b ${ }^{\text {high }} \mathrm{Ly}^{6 \mathrm{G}^{\text {high }}}$ neutrophil count in hearts injected with CMCs was increased $(69.7 \pm 8.7$ vs $242 \pm 41.3$ cells per mg of tissue, $P<0.01)$. Further analysis showed that both subpopulations of pro-inflammatory N1 (CD206 ${ }^{\text {low }}$ ) and pro-reparative N2 $\left(\mathrm{CD} 206^{\mathrm{high}}\right)$ neutrophils were significantly increased in response to CMC injection (N1, 26.1 \pm 4.8 vs 95.2 \pm 17.7 , $P<0.01$; N2, $46.7 \pm 5.2$ vs $136.9 \pm 21.9$ cells per $m g$ of tissue, $P<0.01$ ) (Fig. $2 \mathrm{~A}, \mathrm{~B}$ ). Taken together, these data indicate that CMC injection recruits both $\mathrm{N} 1$ and $\mathrm{N} 2$ neutrophil populations.

CMC secretome has chemotactic and anti-apoptotic effects on neutrophils in vitro. Neutrophils are short-lived cells. Once they extravasate into the myocardium, they die by apoptosis or NETosis within a few hours. Their life span can be extended when exposed to pro-inflammatory cytokines. We hypothesized that the number of neutrophils in the heart after CMC injection increases both because of recruitment and prolonged cell survival. To test this hypothesis, we collected conditioned media from CMCs and performed chemotaxis assay with modified Boyden chamber plates. We found that CMC-conditioned media has a strong dose-dependent chemoattractant activity for neutrophils (Fig. 2C). Next, we tested the effect of CMC conditioned media on neutrophil survival. We isolated bone marrow neutrophils and subjected them to serum starvation-induced apoptosis. We detected apoptosis in neutrophils with Annexin V and PI staining and quantified it with flow cytometry (Fig. 2D). Serum starvation induced robust neutrophil apoptosis (52.9 $\pm 0.7 \%$ Annexin $V^{p o s}$ cells), which was significantly reduced in the presence of CMC-conditioned media $\left(32.3 \pm 1.2 \%\right.$ Annexin $\mathrm{V}^{\text {Pos }}$ cells, $P<0.001$ ) (Fig. 2E). Further stratification for early and late apoptosis with PI staining indicated that both phases of apoptosis were significantly reduced in the presence of CMC-conditioned media (Fig. 2E). Together, these data suggest that the increased number of neutrophils after CMC injection may be due to both increased migration and survival induced by CMC paracrine factors.

CMC injection recruits Ly6 $\mathrm{C}^{\text {high }}$ monocytes and increases macrophages in infarcted hearts. Myocardial damage due to ischemia recruits two populations of monocytes, identified on the basis of Ly6C expression. Ly6 $\mathrm{C}^{\text {high }}$ monocytes are proinflammatory, whereas Ly6 $\mathrm{C}^{\text {low }}$ monocytes are patrolling monocytes with anti-inflammatory and pro-reparative cytokine profiles. Interestingly, the recruitment of both monocyte populations is essential for proper infarct healing and timely scar formation ${ }^{18}$. We found that intramyocardial administration of CMCs increased both Ly6C high (vehicle 19.4 \pm 1.8 , CMCs $54.8 \pm 7.5$ cells per mg of tissue, $P<0.01$ ) and Ly6C low monocytes (vehicle 32.3 \pm 5.5 , CMCs $68.0 \pm 14.61$ cells per mg of tissue, $P<0.01$ ) measured 7 days after cell injection (Fig. 3A, C). Next, we used flow cytometry to enumerate the number of macrophages in hearts injected with CMCs and vehicle. We stratified the macrophage population into two subpopulations based on the expression of Ly6C. We found that both Ly6C high and Ly6C $\mathrm{C}^{\text {low }}$ macrophages were significantly increased in CMC-injected hearts (Ly6Chigh $27.0 \pm 3.3$ vs $46.7 \pm 6.2, P<0.05$; Ly6C ${ }^{\text {low }} 153.2 \pm 21.4$ vs $270.4 \pm 28.8$ cells per mg of tissue, $P<0.05$ ) (Fig. 3B, D). Because the total number of macrophages in post-MI hearts is determined by the infiltration of monocytes that further differentiate to macrophages and by the proliferation of already differentiated macrophages, we speculate that the increased number of macrophages in CMC-injected hearts is partially due to recruitment of monocytes.

CMCs have a pro-migratory effect on bone marrow-derived monocytes. Because we found in our in vivo experiments that CMC injection recruits monocytes, we reasoned that CMCs may induce monocyte migration via secretion of chemotactic factors. To test this hypothesis, we collected conditioned media from CMCs and used modified Boyden chamber plates to test the migratory activity of bone marrow monocytes. We 
A.

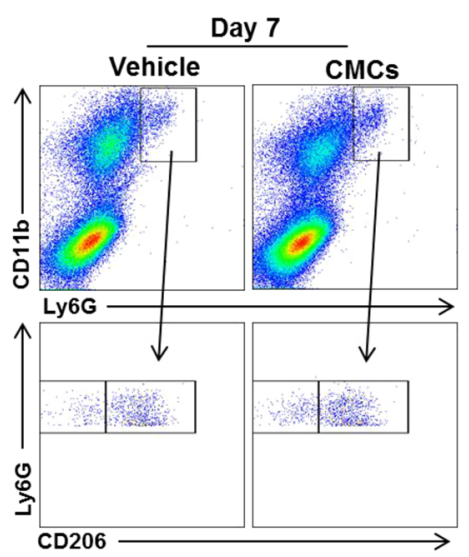

c.

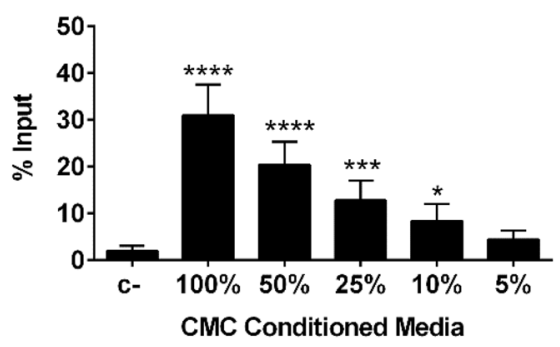

B.
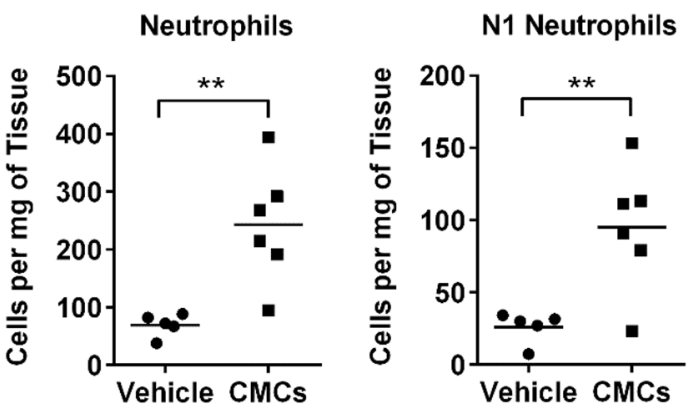

N2 Neutrophils

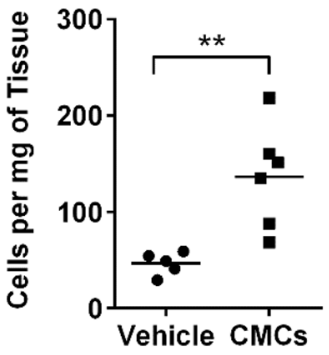

D.

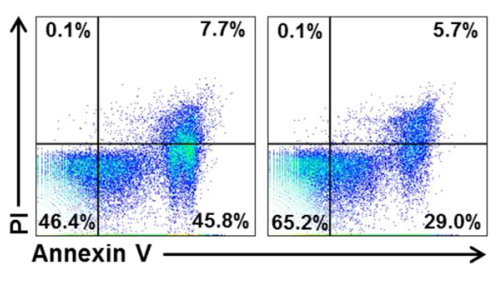

E.

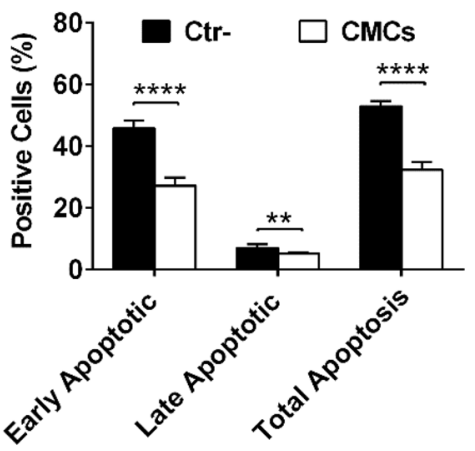

Figure 2. Effects of CMCs on neutrophils in vitro and in vivo. CMCs $\left(5 \times 10^{5}\right)$ were injected in the mouse hearts $2 \mathrm{~d}$ after MI. Seven days later, hearts were harvested and neutrophils were detected with flow cytometry (A), and quantified (B). Number of cells shown as mean; sham $n=5, M I=6 ;{ }^{* \star} P<0.01$ (unpaired t test). Bone marrow neutrophils were subjected to migration assay with modified Boyden chamber plates to CMC conditioned media. Number of migrated cells shown as mean \pm SEM; $n=5 ;{ }^{\star} P<0.05 ;{ }^{\star \star \star} P<0.001 ;{ }^{\star * \star *} P<0.0001$ (one-way ANOVA) (C). Bone marrow neutrophils were cultured in serum depleted media for $24 \mathrm{~h}$ in the presence or absence of CMCs conditioned media. Apoptotic cells were detected with Annexin V/PI staining (D) and quantified with flow cytometry (E). Number of apoptotic cell shown as mean \pm SEM; $\mathrm{n}=5 ;{ }^{* \star} P<0.01$; ${ }_{* * * *} P<0.0001$ (multiple $t$ test).

found that monocytes exhibit a dose-dependent increase in migratory response to conditioned media (Fig. 4A). These data suggest that the secretome of CMCs can directly recruit immune cells, including monocytes and neutrophils, via secreted paracrine factors.

The secretome of CMCs increases macrophage survival and phagocytosis, and reduces macrophage pro-inflammatory activation. The number of macrophages in the infarcted myocardium depends on the recruitment of monocytes, but also is regulated by proliferation and survival of cardiac monocyte-derived macrophages. As described above, we found that monocytes have a strong chemotactic response to $\mathrm{CMC}$ conditioned media. Here, we tested the effect of CMC secretome on the survival/proliferation of monocyte-derived macrophages in vitro. Bone marrow macrophages and CMCs were co-cultured using a transwell system in which secreted factors can be exchanged via a porous membrane without direct contact of co-cultured cells. We found that after a 24 -h co-culture, the number of naïve macrophages was significantly increased in the presence of CMCs $(\sim 128 \%$ of control, $P<0.05)$. However, CMC secretome had no effect on M1 or M2 polarized macrophage survival/proliferation (Fig. 4B). The main role of macrophages as phagocytes in wound healing is to remove dead cells via phagocytosis. Next, we used the same co-culture system to evaluate macrophage phagocytosis. After a 24-h co-culture, transwells containing CMCs were removed and macrophages were stimulated with latex beads opsonized with FITC labeled IgG for $1 \mathrm{~h}$. Subsequently, macrophages were detached from dishes and analyzed for the efficiency of phagocytosis with flow cytometry. We found that macrophages co-cultured with CMCs had increased phagocytic activity regardless of macrophage polarization status (M0, M1, or M2) (Fig. 4C).

Macrophages recruited to the damaged myocardium not only remove dead cells via phagocytosis, but also secrete cytokines that shape the immune response and regulate activation of fibroblasts and angiogenesis. In response to danger-associated molecular patterns (DAMPs), macrophages become activated and secrete proinflammatory cytokines, perpetuating inflammation and contributing to worsening cardiac function. To mimic the pro-inflammatory response of macrophage to DAMPs, we stimulated macrophages with LPS and IFN- $\gamma$, 
A.
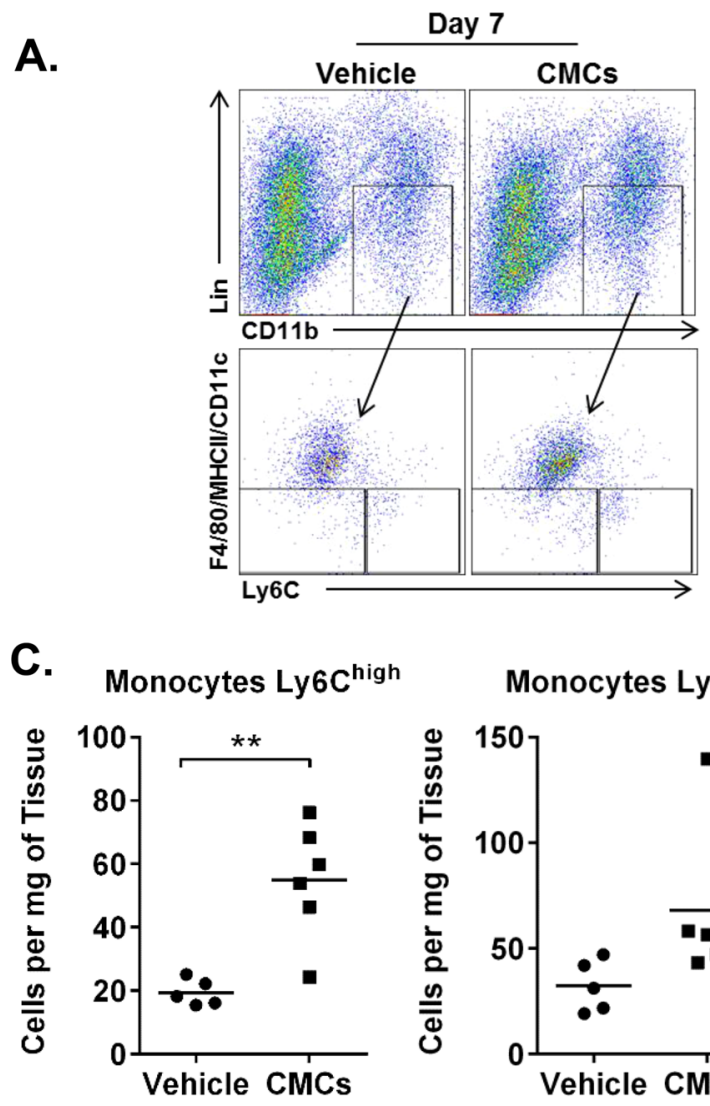

Day 7

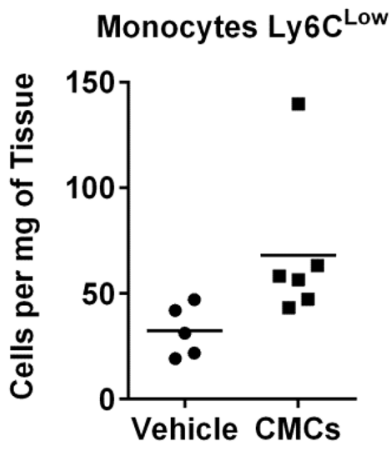

B.

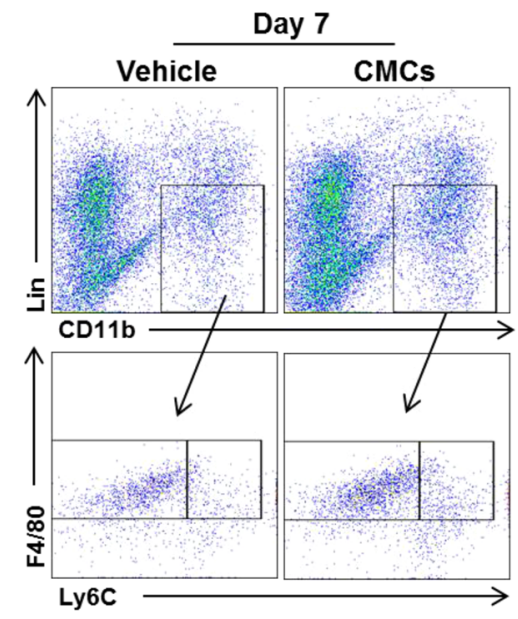

D.

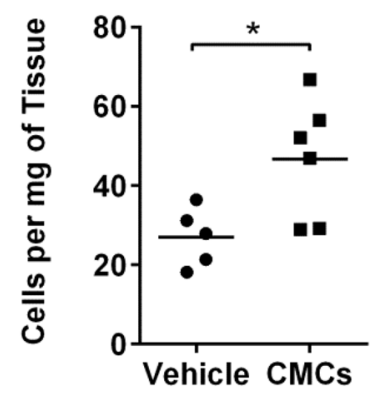

Macrophages Ly6C low

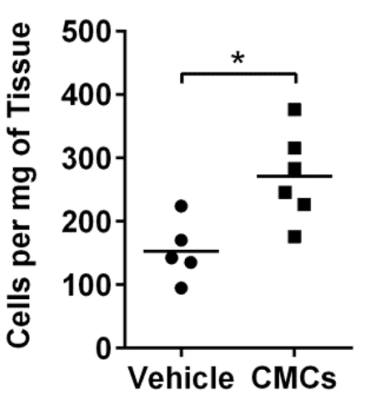

Figure 3. Intramyocardial injection of CMCs increases monocytes and macrophages in infarcted mouse hearts. CMCs $\left(5 \times 10^{5}\right)$ were intramyocardially injected in the mouse hearts $2 \mathrm{~d}$ after MI. Seven days later, hearts were harvested and monocytes and macrophages were detected with flow cytometry ( $\mathbf{A}$ and $\mathbf{B}$ respectively), and quantified (C and $\mathbf{D}$ respectively). Number of cells shown as mean; sham $n=5, \mathrm{MI} n=6 ;{ }^{\star} P<0.05 ;{ }^{\star \star} P<0.01$ (unpaired t test).

which elicited strong pro-inflammatory Il1 $a, I l 1 b$, Il6, and Il12b gene expression in macrophage. In the presence of CMCs, the pro-inflammatory activation of CMCs was significantly reduced (Fig. 4D). Moreover, CMC conditioned media enhacend pro-reparative (Arg1, Fizz1, Chil4) and reduced pro-fibrotic ( $\mathrm{Tg} f b 2$ and $\mathrm{Tg} f b 3$ ) gene program induced with IL-4 and IL-13 (Fig. 4D). To determine the impact of CMCs on cardiac macrophages in vivo, we sorted macrophages from infarcted hearts $7 \mathrm{~d}$ after CMC or vehicle injection and subjected them to gene expression profiling with qPCR arrays. We found that macrophages isolated from hearts injected with CMCs exhibited numerous changes in gene expression related to immunoregulation and repair compared with vehicleinjected hearts (Supplementary Fig. 3). Taken together, these data indicate that CMCs have strong immunomodulatory effects on macrophages, both in vivo and in vitro. Administration of CMCs to infarcted hearts can regulate not only the number of macrophages, but also their function related to immunomodulation and tissue repair.

CMCs have no effects on lymphocyte numbers in vivo. Both $\mathrm{B}$ and $\mathrm{T}$ lymphocytes are involved in infarct healing and scar formation ${ }^{14}$. Here, we tested the impact of CMC injection on B and T cell infiltration into infarcted mouse hearts. We found that B lymphocytes expressing CD19 or B220 did not increase in the myocardium after CMC injection. Similarly, the total number of T lymphocytes (CD3 ${ }^{\text {pos }}$ ) was not changed after CMC injection, and there was no effect on Tc CD $8^{\text {pos }}$ or Th CD4 $4^{\text {pos }}$ lymphocyte recruitment (Fig. 5). These data indicate that, after intramyocardial injection, CMCs secrete factors that recruit innate immune cells but not B or T lymphocytes.

CMCs express CC and CXC chemokines regulating migration of neutrophils and monocytes. Monocyte and neutrophil migration is regulated by numerous CC and CXC chemokines ${ }^{13,20}$. We performed RNAseq and mined the data to detect CC and CXC chemokines. We found that CCL2, CCL7, CCL25, CXCL1, and CXCL12 were highly expressed at the mRNA level in CMCs (Fig. 6A, B). Next, we validated expression of these chemokines in CMC-conditioned media with chemokine protein array. We found particulary strong signal for CXCL1, CXCL12, CCL2, and CCL5 chemokines; and positive but weak signal for CXCL2, CXCL10, CCL5, and CCL9/10 (Fig. 6C). All these chemokines have been implicated in regulation of immune cell trafficking via activation of specific receptors. Next, we used chemokine receptor antagonists to identify which of the CMC-sectered chemokine contributes to chemotaxis of bone marrow immune cells. We found 
A.

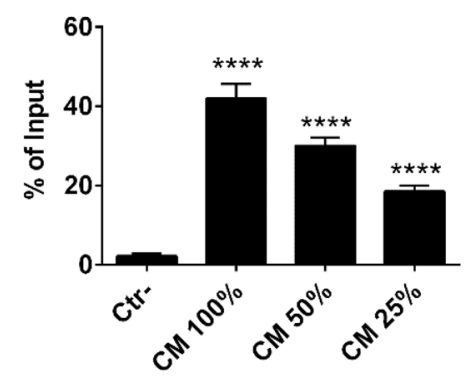

C.

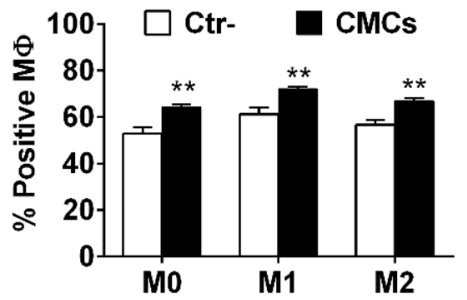

D.

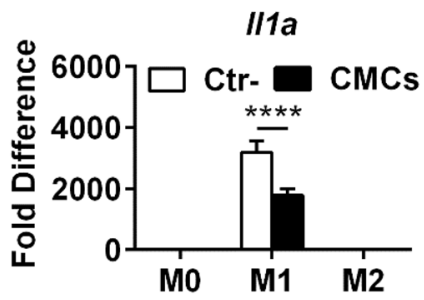

II12b

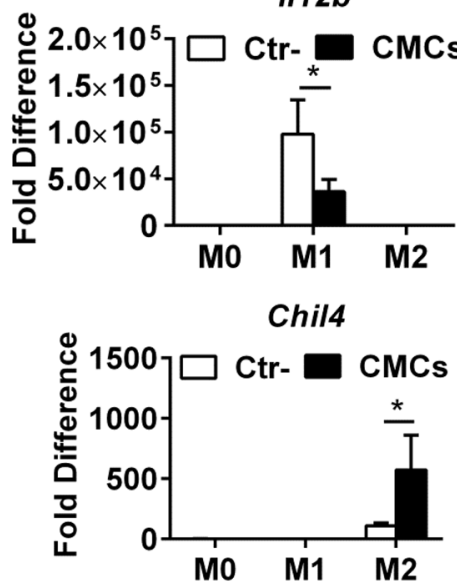

B.

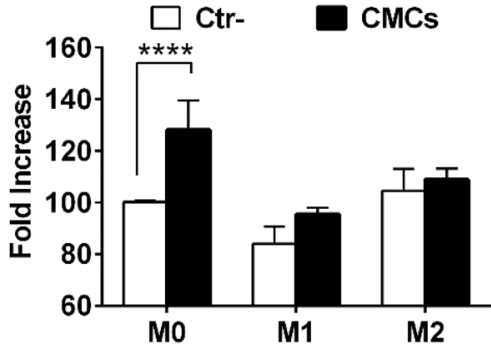

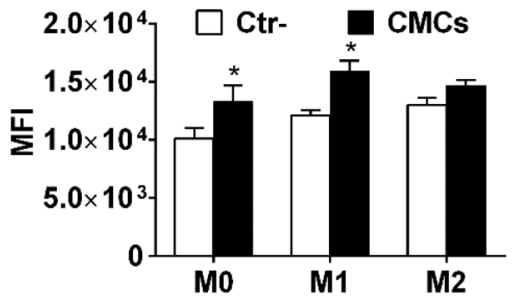

II1b

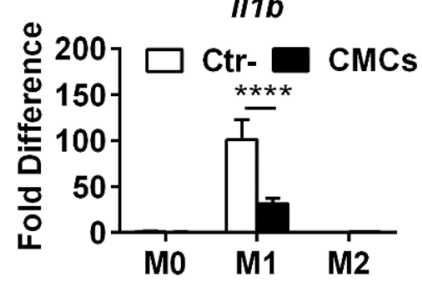

Arg1

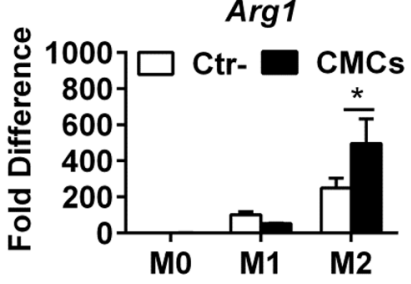

Tgfb2

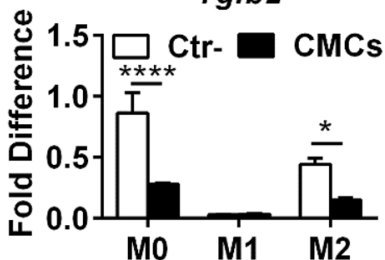

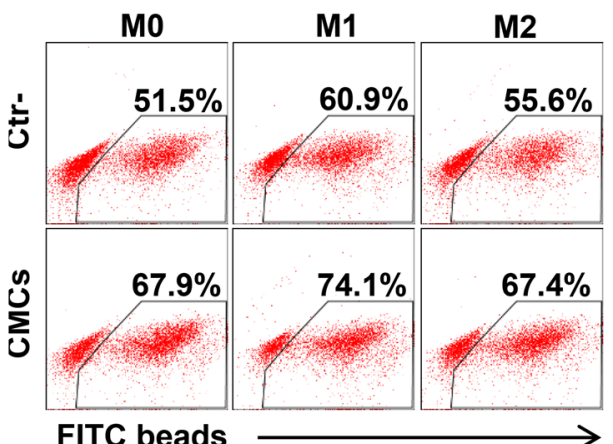

116

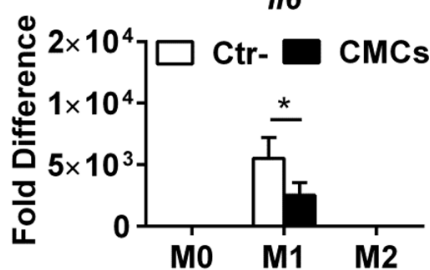

Fizz1

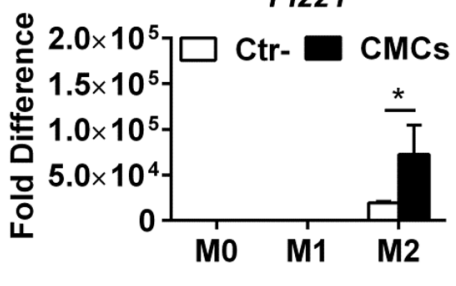

Tgfb3

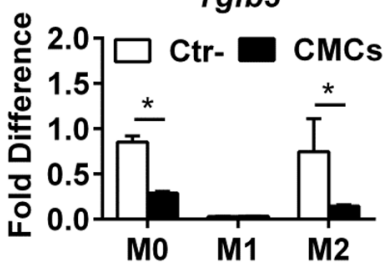

Figure 4. CMC secretome increases monocyte migration and macrophage proliferation, phagocytosis, and inhibits pro-inflammatory activation in vitro. Bone marrow monocytes were subjected to migration assay with modified Boyden chamber plates to CMC conditioned media. Number of migrated cells shown as mean $\pm \mathrm{SEM}$; $\mathrm{n}=4 ;{ }^{* * * *} \mathrm{P}<0.0001$ (one-way ANOVA) (A). Naïve bone marrow macrophages (M0) were stimulated with LPS $(100 \mathrm{ng} / \mathrm{mL})$ and IFN $\gamma(20 \mathrm{ng} / \mathrm{mL})(\mathrm{M} 1)$, or IL-4 $(10 \mathrm{ng} / \mathrm{mL})$ and IL-13 $(10 \mathrm{ng} / \mathrm{mL})$ in the precence CMC conditioned media or control media. After $24 \mathrm{~h}$ macrophage number was evaluated with microscopy (B); phagocytosis of FITC IgG opsonized latex beads was determined with flow cytometry (C), and expression of pro-inflammatory gene expression was quantified with qPCR (D). Data are means \pm SEM; $\mathrm{n}=6 ;{ }^{\star} P<0.05$; ${ }^{* *} P<0.01 ;{ }^{* * *} P<0.0001$ (one-way ANOVA). 
A.
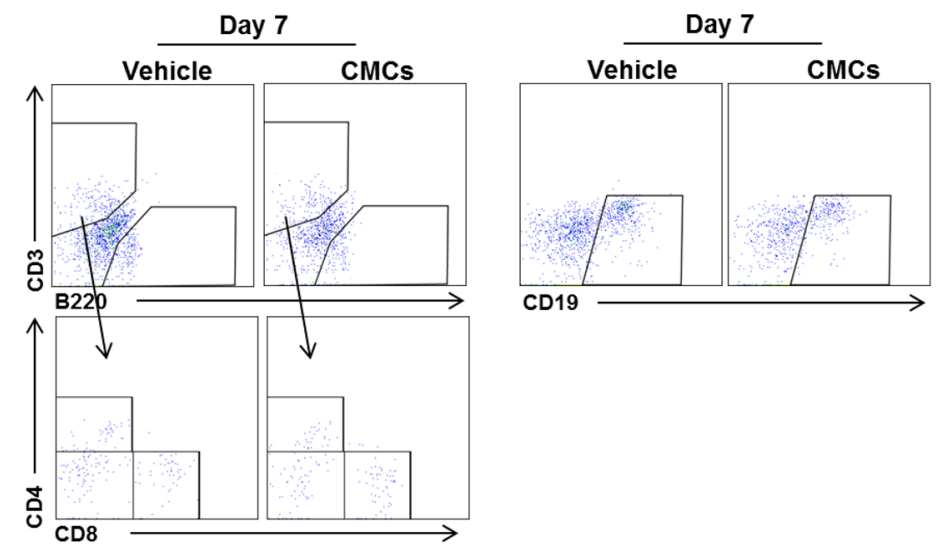

B.
B cells $B 220$

\section{B cells CD19}
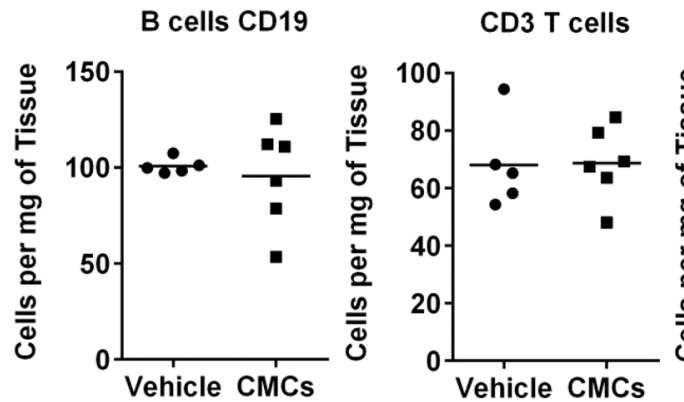

Vehicle CMCs

Th cells $\mathrm{CD}^{+}{ }^{\mathrm{CD}} 4^{+}$

Tc cells $\mathrm{CD}^{+} \mathrm{CD}^{+}$

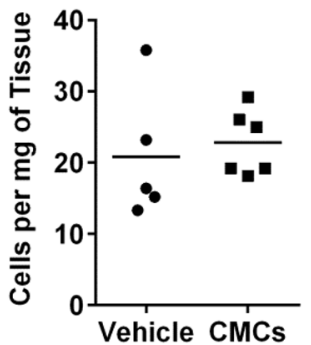

Figure 5. Intramyocardial injection of CMCs has no effect on $\mathrm{B}$ and $\mathrm{T}$ cell number in vivo. CMCs $\left(5 \times 10^{5}\right)$ were intramyocardially injected in the mouse hearts $2 \mathrm{~d}$ after MI. Seven days later, hearts were harvested and B and T cells were detected with flow cytometry (A), and quantified (B). Number of cells shown as mean; sham $n=5$, MI $\mathrm{n}=6$; (unpaired $t$ test).

tor antagonists (Fig. 6D). These data suggest that the CXCL12-CXCR4, CXCL1/CXCL2-CXCR2, and CCL2/ CCL7-CCR2 chemokine-chemokine receptor axes are involved in migration of neutrophils and monocytes to the infarcted heart after CMC administration (Fig. 6E). This hypothesis would have to tested in further experiments in vivo.

\section{Discussion}

Our recent studies ${ }^{4,5,26}$ have shown that administration of CMCs improves cardiac function after MI without longterm engraftment or regeneration. Because the immune system plays an importand role in myocardial healing, the main goal of this work was to test the immunomodulatory properties of CMCs in vitro and in vivo. The main results can be summarized as follows: (1) at the time of CMC injection ( $2 \mathrm{~d}$ after a reperfused MI), the infarcted murine myocardium is infiltrated by neutrophils, monocytes, macrophages with pro-inflammatory phenotype, and cytotoxic T cells; (2) expression of genes for both pro- and anti-inflammatory cytokines is significantly increased at this time; (3) Intramyocardial CMC injection further increases recruitment of neutrophils, monocytes, and macrophages, whereas the number of B and T lymphocytes remains unchanged; (4) in vitro, the CMC secretome exerts strong chemotactic and pro-survival actions on neutrophils, induces migration of monocytes, increases survival and phagocytosis of macrophages, decreases pro-inflammatory activation of macrophages in response to LPS and IFN $\gamma$, and enhances a pro-reparative gene program after IL- 4 and IL-13 stimulation. Taken together, these data demonstrate that CMCs have strong, heretofore unknown immunomodulatory properties for myeloid cells both in vitro and in vivo, but have no effects on B and T cells.

Although previous investigations have suggested that cell therapy affects innate immunity after acute $\mathrm{MI}^{1,35}$, to our knowledge this is the first study to identify immunoregulatory actions of CMCs in this setting. The data reveal a potential mechanism that may underlie the beneficial actions of CMCs in acute $\mathrm{MI}^{5}$. The study by Vagnozzi et $\mathrm{al}^{35}$ showed that intramyocardial injection of bone marrow MNC and c-kit ${ }^{\text {pos }}$ cardiac progenitors recruits monocytes and macrophages in naïve hearts. In our studies, we profiled immune cell infiltration in response to CMC injection in infarcted hearts. This was also the first study to indentify changes in a broad spectrum of immune cells (neutrophils, monocytes, macrophages, B and T cells) in response to CMCs in the setting of acute MI.

The immune response after acute MI is a dynamic and finely regulated series of events that culminates in scar formation. Tissue necrosis caused by myocardial ischemia elicits a strong immune response via activation of the complement system, production of reactive oxygen species (ROS), release of DAMPs, and secretion of chemokines ${ }^{13-15,17,20}$. In mouse hearts, this phase begins within minutes and lasts for up to 4 days after a nonreperfused infarction ${ }^{13,14,17-20}$. In our study, we used ischemia followed by reperfusion, which is known to result in faster resolution than permanent coronary ligation ${ }^{17}$. The reperfused MI model is more relevant to the clinical 
A.

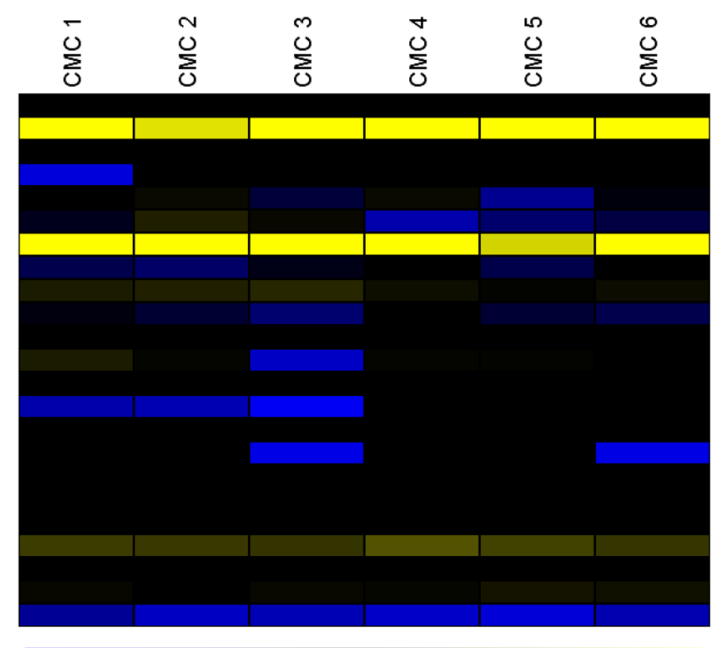

Ccl1
Cc12
Cc13
Cc14
Cc15
Cc16
Cc17
Cc18
Cc19
Cc11
CcL12
Cc117
Cc19
Cc120
Cc121a
Cc121c
Cc121b
Cc122
Cc124
Cc125
Cc126
Cc127a
Cc128

Low
Medium

High
B.

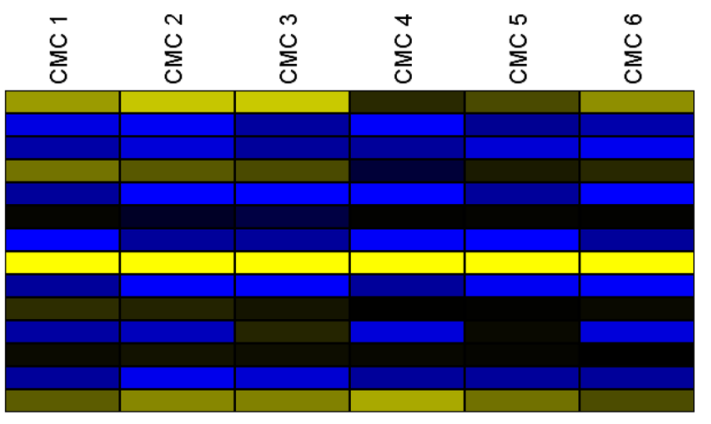

Cxcl1

Cxc12

$\mathrm{Cxcl3}$

Cxc19

Cxc19

Cxcl11

Cxcl12

Cxcl13

Cxcl14

Cxcl15

Cxc116

Cxc16

Cx3cl1

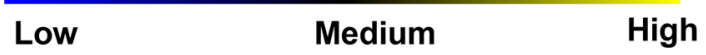

C.

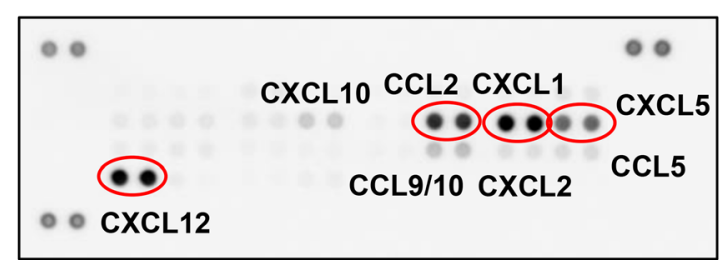

E.

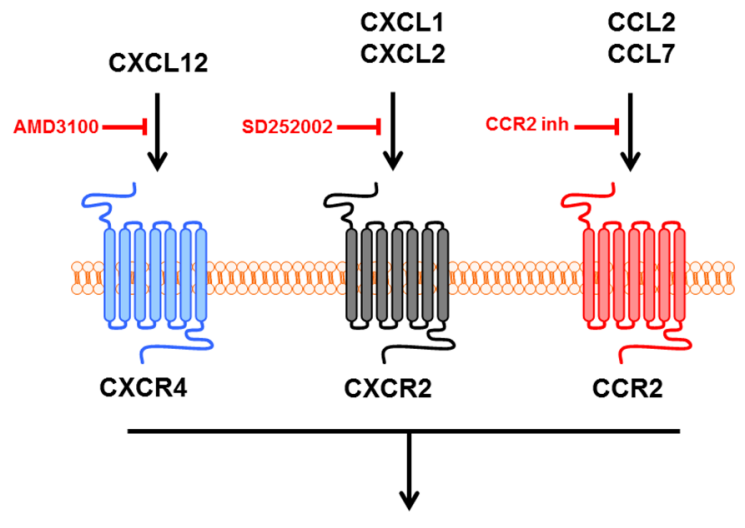

Chemotaxis

Figure. 6. CMCs secrete chemokines for neutrophils and monocytes. Expression of CC (A) and CXC chemokines (B) was determined with RNAseq. Expression of CC and CXC chemokines in CMC conditioned media was evaluated with Chemokine $\operatorname{Array}(\mathbf{C})$. Bone marrow cells were subjected to migration assay with modified Boyden chamber plates to CMC conditioned media in the presence of AMD3100, SD252002, or CCR2 inhibitor (D). Number of migrated cells shown as mean \pm SEM; $n=4 ;{ }^{\star} P<0.05 ;{ }^{\star * \star} P<0.001 ;{ }^{\star \star \star \star} P<0.0001$ (oneway ANOVA). Schematic of chemokine-chemokine receptor interaction (E).

situation because in contemporary medical practice almost all MIs are reperfused, either spontaneously or iatrogenically. We found that $2 \mathrm{~d}$ after reperfusion and at the time of cell injection, the myocardium was still heavily infiltrated by pro-inflammatory $\mathrm{N} 1$ neutrophils and Ly6 $\mathrm{C}^{\text {high }}$ monocytes, suggesting that $\mathrm{CMC}$ injection occurred during the initial pro-inflammatory phase. This conclusion is further supported by the expression of genes encoding the pro-inflammatory cytokines $I l 1 b, I l 6, \operatorname{Tnf} a$ and the chemokine Ccl2. This initial pro-inflammatory period resolves within a few days and is followed by a reparative phase dominated by macrophages, lymphocytes, and proliferating scar-forming myofibroblasts ${ }^{13,14,20-22,30}$. The absence of $\mathrm{B}$ and $\mathrm{T}$ lymphocytes at $2 \mathrm{~d}$ after reperfusion further supports the conclusion that CMC injection occurred during the initial pro-inflammatory phase. Because at the time of CMC injection the myocardium is infiltrated with neutrophils, monocytes, and macrophages, but not with $\mathrm{B}$ and $\mathrm{T}$ cells, we decided to focus mainly on the interaction between CMCs with myeloid immune cells.

Neutrophils are the first immune cells infiltrating myocardium after infarction. Recruited neutrophils secrete proteolitic enzymes (hydrolases, elastase, neutral serine proteases, lysozyme, cathepsins), which degrade necrotic tissue and facilitate clearance of dead cells and extracellular matrix debris. Moreover, extravasated neutrophils produce proinflammatory mediators including cytokines (IL-1, IL-6, TNF- $\alpha$ ), ROS, and extracellular traps that perpetuate the inflammatory response, thereby producing cytoxic effects and further contributing to myocardial injury ${ }^{13,14,36,37}$. Neverthless, neutrophil recruitment is necessary for proper myocardial recovery after infarction. Systemic neutrophil depletion leads to dysregulated monocytes/macrophage function, promotes excess 
ECM deposition, and worsens cardiac function ${ }^{19}$. Therefore, neutrophils can have a dual role in the process of myocardial healing.

Little is known about the effect of cell therapy on neutrophil function after MI. We found that intramyocardial injection of CMCs increased the number of both N1 and N2 neutrophil subpopulations, and that the CMC secretome exerts strong chemotactic and pro-survival activity on neutrophils. This suggests that the increased number of neutrophils after CMC injection could be caused by the CMC secretome though both mechanisms. Previous studies have shown that bone marrow MSCs exert immunomodulatory actions on neutrophils similar to CMCs. For example, in vitro experiments have demonstrated that co-culture of bone marrow MSCs increases survival of neutrophils; this anti-apoptotic effect of MSCs was mediated by secretion of IL-6, IFN- $\beta$, and GM-CSF ${ }^{38}$. In contrast, intramyocardial injection of human cord blood mononuclear cells, which contain both hematopietic and mesenchymal cells, in immunocompetent rats at the time of permanent coronary ligation leads to reduced infiltration of neutrophils ${ }^{39}$. This apparent discrepancy with our study could be due to numerous differences, including cell type, model of MI, time of cell administration, and follow-up interval for evaluation of immune cell infiltration $^{39}$. The mechanism of increased neutrophil migration after CMC injection is unclear. We found that CMCs secrete numberous chemokines that act on neutrophils, including CXCL12, CCL2, CXCL1, and CXCL2. Determining the role of these CMC-secreted chemokines in the recruitment of neutrophils will require further in vivo and in vitro investigations.

Recent studies have established a critical role of monocytes/macrophages in myocardial repair after infarction ${ }^{14,15,18,23-25}$. Monocytes recruitment to the infarcted myocardium is a dynamic process which occurs in two phases. In the first phase, recruitment of pro-inflammatory Ly6 $\mathrm{C}^{\text {high }}$ monocytes promotes tissue degradation though secreted proteases. Reparative Ly6C $\mathrm{C}^{\text {low }}$ monocytes are then recruited to resolve inflammation and promote infarct healing ${ }^{14,18}$. As the pro-inflammatory phase resolves, Ly6 $\mathrm{C}^{\text {high }}$ monocytes differentiate to reparative Ly $6 C^{\text {low }}$ macrophages, which promote wound repair and scar formation. We found that intramyocardial injection of CMCs facilitates recruitment of both Ly6 $\mathrm{C}^{\text {high }}$ and Ly $6 \mathrm{C}^{\text {low }}$ monocytes. That this process is mediated by chemokines produced by CMCs is supported by our finding that monocytes have strong chemotactic activity to CMC-conditioned media. Moreover, we found that CMCs secrete CCL2 and CX3CL1, which are strong chemoattractans for Ly6 $C^{\text {high }}$ and Ly6 $C^{\text {low }}$ monocytes, respectively ${ }^{14,18,40}$. Further studies will be necessary to determine the role of CMC-secreted chemokines in the recruitment of monocytes in vivo.

The number of macrophages in the heart after $\mathrm{MI}$ is regulated both by recruitment of monocytes and proliferation of local cardiac macrophages ${ }^{41}$. Our finding that CMC injection increases the myocardial content of Ly6C ${ }^{\text {low }}$ macrophages could be explained by increased recruitment of monocytes (discusses above) or enhanced proliferation/survival of cardiac macrophages. Since our in vitro studies show that co-culture with CMCs increases macrophage survival/proliferation, this could be a contributing mechanism to the increased number of macrophages. The macrophages recruited after MI can orchestrate the immune response by secreting proinflammatory cytokines (IL-1, IL-6, TNF- $\alpha$ ) and chemokines (CCL2); in addition, they can promote repair and scar formation via secretion of cytokines that activate myofibroblast differentation (TGF $\beta$ and IL-10), via angiogenesis (VEGF), and via release of MMPs and TIMPs that regulate the extracellular matrix (ECM) network ${ }^{15,23,40}$. The macrophage shift from inflammatory to reparative phenotypes may be a direct consequence of macrophage function: efferocytosis, the uptake of apoptotic cells, reduced pro-inflammatory cytokine production and upregulated pro-reparative and anti-inflammatory cytokines (IL-10 and TGF- $\beta)^{42}$. Our finding that macrophages co-cultured with CMCs exhibit increased phagocytosis suggests that CMC-secreted factors facilitate apoptotic cell removal and reduce pro-inflammatory cytokine production. In separate experiments, we found that co-culture with CMCs inhibits the pro-inflammatory activation of macrophages in response to LPS and IFN- $\gamma$. This suggests that CMCs enhance recruitment of macrophages, but also facilitate their phenotype swich directly by modulating their response to pro-inflammatory stimuli and also indirectly by facilitating their phagocytosis.

Similar immunomodulatory effects have been reported using other cells types. In in vitro co-culture systems, it has been shown that the secretome of BM MSCs facilitates switch of macrophages from pro-inflammatory to pro-reparative and enhaces their phagocytic activity ${ }^{43}$. Several MSC-derived factors have been identified that modulate macrophage function, including prostaglandin E2, indoleamine 2,3-dioxygenase, TGF- $\beta$, and IL-10 $0^{1,44-46}$. Furthermore, infusion of BM MSCs at $2 \mathrm{~d}$ after MI in mice induces a macrophage switch from proinflammatory toward a reparative phenotype ${ }^{43}$. In addition, the secretome of cardiosphere-derived cells (CDCs) has been shown to activate the reparative program in macrophages and decrease the expression of CD80 and CD86, which are co-stimulatory receptors necessary for T cell activation. In vivo injection of CDCs in rats soon after reperfuction results in improvement of LV function, but also decreases the number of myocardial CD68 $8^{\text {pos }}$ macrophages ${ }^{47,48}$. These studies further support the conclusion that cell therapy has immunomodulatory effects. It seems likely that the time of cell injection has an impact on immune cell recruitment.

Our data and reports by others ${ }^{1,38,39,43,46-48}$ indicate that cell therapy has immunomodulatory actions on macrophages and neutrophils, both in vivo and in vitro. However, whether these actions are important for the beneficial effects of cell therapy remains unclear. Since neutrophils and macrophages play a key role in wound repair and scar formation after MI, and since systemic depletion of neutrophils or macrophages causes dysregulated immune response, impaired scar formation, and decreased cardiac function after $\mathrm{MI}^{16,18,19,23,25}$, immune cell depletion would not be an optimal strategy to address the question of whether the salutary effects of cell therapy rely on immunomodulatory actions on neutrophils and macrophages. Such a strategy, however, may be useful in models of chronic heart failure, in which cells are infused after the acute inflammatory response has resolved and temporary depletion of neutrophils or macrophages would not have a substantial impact on cardiac function. Another challenge is to identify the immunomodulatory mediators that are secreted by the injected cells. Since CMCs secrete numerous factors that can work synergistically to modulate the immune system, it may be difficult to pinpoint the factor(s) responsible for the immunomodulatory and salutary effects of the injected cells. 
The present results provide new insights into the actions of CMCs transplanted in the acute phase of MI. The modulatory effects of CMCs on innate, but not adaptive, immune cells described herein could facilitate elucidation of the mechanism of action of CMC-based therapy and cell therapy in general. Ultimately, improved understanding of the immunomodulatory actions of cell therapy may help harness the immune system to ameliorate the outcome of ischemic heart disease.

Received: 30 March 2020; Accepted: 19 August 2020

Published online: 08 September 2020

\section{References}

1. Wysoczynski, M., Khan, A. \& Bolli, R. New paradigms in cell therapy: repeated dosing, intravenous delivery, immunomodulatory actions, and new cell types. Circ. Res. 123, 138-158. https://doi.org/10.1161/CIRCRESAHA.118.313251 (2018).

2. Banerjee, M. N., Bolli, R. \& Hare, J. M. Clinical studies of cell therapy in cardiovascular medicine: recent developments and future directions. Circ. Res. 123, 266-287. https://doi.org/10.1161/CIRCRESAHA.118.311217 (2018).

3. Moore, J. B. T. et al. Epigenetically modified cardiac mesenchymal stromal cells limit myocardial fibrosis and promote functional recovery in a model of chronic ischemic cardiomyopathy. Basic Res. Cardiol. 114, 3. https://doi.org/10.1007/s00395-018-0710-1 (2018).

4. Wysoczynski, M. et al. A new method to stabilize c-kit expression in reparative cardiac mesenchymal cells. Front Cell Dev. Biol. 4, 78. https://doi.org/10.3389/fcell.2016.00078 (2016).

5. Wysoczynski, M. et al. Myocardial reparative properties of cardiac mesenchymal cells isolated on the basis of adherence. J. Am. Coll. Cardiol. 69, 1824-1838. https://doi.org/10.1016/j.jacc.2017.01.048 (2017).

6. Hobby, A. R. H. et al. Cortical bone-derived stem cell therapy reduces apoptosis after myocardial infarction. Am. J. Physiol. Heart Circ. Physiol. 317, H820-H829. https://doi.org/10.1152/ajpheart.00144.2019 (2019).

7. Sharp, T. E. 3rd. et al. Cortical bone stem cell therapy preserves cardiac structure and function after myocardial infarction. Circ. Res. 121, 1263-1278. https://doi.org/10.1161/CIRCRESAHA.117.311174 (2017).

8. Hong, K. U. et al. c-kit+ cardiac stem cells alleviate post-myocardial infarction left ventricular dysfunction despite poor engraftment and negligible retention in the recipient heart. PLOS ONE 9, e96725. https://doi.org/10.1371/journal.pone.0096725 (2014).

9. Hong, K. U. et al. A highly sensitive and accurate method to quantify absolute numbers of c-kit+ cardiac stem cells following transplantation in mice. Basic Res. Cardiol. 108, 346. https://doi.org/10.1007/s00395-013-0346-0 (2013).

10. Gnecchi, M. et al. Paracrine action accounts for marked protection of ischemic heart by Akt-modified mesenchymal stem cells. Nat. Med. 11, 367-368. https://doi.org/10.1038/nm0405-367 (2005).

11. Gnecchi, M., Zhang, Z., Ni, A. \& Dzau, V. J. Paracrine mechanisms in adult stem cell signaling and therapy. Circ. Res. 103, 1204-1219. https://doi.org/10.1161/CIRCRESAHA.108.176826 (2008).

12. Mirotsou, M., Jayawardena, T. M., Schmeckpeper, J., Gnecchi, M. \& Dzau, V. J. Paracrine mechanisms of stem cell reparative and regenerative actions in the heart. J. Mol. Cell Cardiol. 50, 280-289. https://doi.org/10.1016/j.yjmcc.2010.08.005 (2011).

13. Frangogiannis, N. G. Regulation of the inflammatory response in cardiac repair. Circ. Res. 110, 159-173. https://doi.org/10.1161/ CIRCRESAHA.111.243162 (2012).

14. Prabhu, S. D. \& Frangogiannis, N. G. The biological basis for cardiac repair after myocardial infarction: from inflammation to fibrosis. Circ. Res. 119, 91-112. https://doi.org/10.1161/CIRCRESAHA.116.303577 (2016).

15. Swirski, F. K. \& Nahrendorf, M. Cardioimmunology: the immune system in cardiac homeostasis and disease. Nat. Rev. Immunol. 18, 733-744. https://doi.org/10.1038/s41577-018-0065-8 (2018).

16. Nahrendorf, M., Pittet, M. J. \& Swirski, F. K. Monocytes: protagonists of infarct inflammation and repair after myocardial infarction. Circulation 121, 2437-2445. https://doi.org/10.1161/CIRCULATIONAHA.109.916346 (2010).

17. Yan, X. et al. Temporal dynamics of cardiac immune cell accumulation following acute myocardial infarction. J. Mol. Cell Cardiol. 62, 24-35. https://doi.org/10.1016/j.yjmcc.2013.04.023 (2013).

18. Nahrendorf, M. et al. The healing myocardium sequentially mobilizes two monocyte subsets with divergent and complementary functions. J. Exp. Med. 204, 3037-3047. https://doi.org/10.1084/jem.20070885 (2007).

19. Horckmans, M. et al. Neutrophils orchestrate post-myocardial infarction healing by polarizing macrophages towards a reparative phenotype. Eur. Heart J. 38, 187-197. https://doi.org/10.1093/eurheartj/ehw002 (2017).

20. Frangogiannis, N. G. Cell biological mechanisms in regulation of the post-infarction inflammatory response. Curr. Opin. Physiol. 1, 7-13. https://doi.org/10.1016/j.cophys.2017.09.001 (2018).

21. Frangogiannis, N. G. Cardiac fibrosis: cell biological mechanisms, molecular pathways and therapeutic opportunities. Mol. Asp. Med. 65, 70-99. https://doi.org/10.1016/j.mam.2018.07.001 (2019).

22. Humeres, C. \& Frangogiannis, N. G. Fibroblasts in the infarcted, remodeling, and failing heart. JACC Basic Transl. Sci. 4, $449-467$. https://doi.org/10.1016/j.jacbts.2019.02.006 (2019).

23. Hulsmans, M., Sam, F. \& Nahrendorf, M. Monocyte and macrophage contributions to cardiac remodeling. J. Mol. Cell Cardiol. 93, 149-155. https://doi.org/10.1016/j.yjmcc.2015.11.015 (2016).

24. Leuschner, F. et al. Rapid monocyte kinetics in acute myocardial infarction are sustained by extramedullary monocytopoiesis. J. Exp. Med. 209, 123-137. https://doi.org/10.1084/jem.20111009 (2012).

25. Swirski, F. K. et al. Identification of splenic reservoir monocytes and their deployment to inflammatory sites. Science 325, 612-616. https://doi.org/10.1126/science.1175202 (2009).

26. Guo, Y. et al. Repeated doses of cardiac mesenchymal cells are therapeutically superior to a single dose in mice with old myocardial infarction. Basic Res. Cardiol. 112, 18. https://doi.org/10.1007/s00395-017-0606-5 (2017).

27. Wysoczynski, M. et al. Poor mobilization in T-cell-deficient nude mice is explained by defective activation of granulocytes and monocytes. Cell Transpl. 26, 83-93. https://doi.org/10.3727/096368916X692221 (2017).

28. Wysoczynski, M. et al. Identification of heme oxygenase 1 (HO-1) as a novel negative regulator of mobilization of hematopoietic stem/progenitor cells. Stem Cell Rev. Rep. 11, 110-118. https://doi.org/10.1007/s12015-014-9547-7 (2015).

29. Ma, Y. et al. Temporal neutrophil polarization following myocardial infarction. Cardiovasc. Res. 110, 51-61. https://doi.org/10.1093/ cvr/cvw024 (2016).

30. Carrillo-Salinas, F. J., Ngwenyama, N., Anastasiou, M., Kaur, K. \& Alcaide, P. Heart inflammation: immune cell roles and roads to the heart. Am. J. Pathol. 189, 1482-1494. https://doi.org/10.1016/j.ajpath.2019.04.009 (2019).

31. Hofmann, U. et al. Activation of CD4+ T lymphocytes improves wound healing and survival after experimental myocardial infarction in mice. Circulation 125, 1652-1663. https://doi.org/10.1161/CIRCULATIONAHA.111.044164 (2012).

32. Li, J. et al. Regulatory T-cells regulate neonatal heart regeneration by potentiating cardiomyocyte proliferation in a paracrine manner. Theranostics 9, 4324-4341. https://doi.org/10.7150/thno.32734 (2019).

33. Leung, O. M. et al. Regulatory T cells promote apelin-mediated sprouting angiogenesis in type 2 diabetes. Cell Rep. 24, 1610-1626. https://doi.org/10.1016/j.celrep.2018.07.019 (2018). 
34. Liang, C. et al. CD8(+) T-cell plasticity regulates vascular regeneration in type-2 diabetes. Theranostics 10, 4217-4232. https://doi. org/10.7150/thno.40663 (2020).

35. Vagnozzi, R. J. et al. An acute immune response underlies the benefit of cardiac stem cell therapy. Nature 577, 405-409. https:// doi.org/10.1038/s41586-019-1802-2 (2020).

36. Mantovani, A., Cassatella, M. A., Costantini, C. \& Jaillon, S. Neutrophils in the activation and regulation of innate and adaptive immunity. Nat. Rev. Immunol. 11, 519-531. https://doi.org/10.1038/nri3024 (2011).

37. Timmers, L. et al. The innate immune response in reperfused myocardium. Cardiovasc. Res. 94, 276-283. https://doi.org/10.1093/ cvr/cvs018 (2012).

38. Cassatella, M. A. et al. Toll-like receptor-3-activated human mesenchymal stromal cells significantly prolong the survival and function of neutrophils. Stem Cells 29, 1001-1011. https://doi.org/10.1002/stem.651 (2011).

39. Henning, R. J. et al. Human cord blood mononuclear cells decrease cytokines and inflammatory cells in acute myocardial infarction. Stem Cells Dev. 17, 1207-1219. https://doi.org/10.1089/scd.2008.0023 (2008).

40. Bajpai, G. et al. Tissue resident CCR2- and CCR2+ cardiac macrophages differentially orchestrate monocyte recruitment and fate specification following myocardial injury. Circ. Res. 124, 263-278. https://doi.org/10.1161/CIRCRESAHA.118.314028 (2019).

41. Sager, H. B. et al. Proliferation and recruitment contribute to myocardial macrophage expansion in chronic heart failure. Circ. Res. 119, 853-864. https://doi.org/10.1161/CIRCRESAHA.116.309001 (2016).

42. Elliott, M. R., Koster, K. M. \& Murphy, P. S. Efferocytosis signaling in the regulation of macrophage inflammatory responses. J. Immunol. 198, 1387-1394. https://doi.org/10.4049/jimmunol.1601520 (2017).

43. Dayan, V. et al. Mesenchymal stromal cells mediate a switch to alternatively activated monocytes/macrophages after acute myocardial infarction. Basic Res. Cardiol. 106, 1299-1310. https://doi.org/10.1007/s00395-011-0221-9 (2011).

44. Francois, M., Romieu-Mourez, R., Li, M. \& Galipeau, J. Human MSC suppression correlates with cytokine induction of indoleamine 2,3-dioxygenase and bystander M2 macrophage differentiation. Mol. Ther. 20, 187-195. https://doi.org/10.1038/mt.2011.189 (2012).

45. Nemeth, K. et al. Bone marrow stromal cells attenuate sepsis via prostaglandin $\mathrm{E}(2)$-dependent reprogramming of host macrophages to increase their interleukin-10 production. Nat. Med. 15, 42-49. https://doi.org/10.1038/nm.1905 (2009).

46. van den Akker, F., Deddens, J. C., Doevendans, P. A. \& Sluijter, J. P. Cardiac stem cell therapy to modulate inflammation upon myocardial infarction. Biochim. Biophys. Acta 2449-2458, 2013. https://doi.org/10.1016/j.bbagen.2012.08.026 (1830).

47. de Couto, G. et al. Macrophages mediate cardioprotective cellular postconditioning in acute myocardial infarction. J. Clin. Invest. 125, 3147-3162. https://doi.org/10.1172/JCI81321 (2015).

48. de Couto, G. et al. Exosomal microRNA transfer into macrophages mediates cellular postconditioning. Circulation 136, $200-214$. https://doi.org/10.1161/CIRCULATIONAHA.116.024590 (2017).

\section{Acknowledgements}

This work was supported by NIH Grants P01 HL078825 (to RB and MW), R01 HL141191 (to MW), and R01 HL141081 (to JBM).

\section{Author contributions}

M.W., R.B., J.K. wrote the main manuscript text. M.W., Y.K., and M.N. prepared figures. Y.K., M.N. Y.G., S.U., T.W., H.L., J.K., J.B.M., S.M., and M.W. conducted experiments. All authors reviewed the manuscript.

\section{Competing interests}

The authors declare no competing interests.

\section{Additional information}

Supplementary information is available for this paper at https://doi.org/10.1038/s41598-020-71580-z.

Correspondence and requests for materials should be addressed to M.W.

Reprints and permissions information is available at www.nature.com/reprints.

Publisher's note Springer Nature remains neutral with regard to jurisdictional claims in published maps and institutional affiliations.

(c) (i)

Open Access This article is licensed under a Creative Commons Attribution 4.0 International License, which permits use, sharing, adaptation, distribution and reproduction in any medium or format, as long as you give appropriate credit to the original author(s) and the source, provide a link to the Creative Commons licence, and indicate if changes were made. The images or other third party material in this article are included in the article's Creative Commons licence, unless indicated otherwise in a credit line to the material. If material is not included in the article's Creative Commons licence and your intended use is not permitted by statutory regulation or exceeds the permitted use, you will need to obtain permission directly from the copyright holder. To view a copy of this licence, visit http://creativecommons.org/licenses/by/4.0/.

(C) The Author(s) 2020 